process, we re-learned the importance of injury data analysis to understand how a consumer product is used in our daily lives with children. Members of the committee, including product design professionals did not know how a child is caught in a baby chair. It is very important to remember that not only professionals' opinions and discussions but also injury data should be fully utilised to establish safety quality requirements for consumer products.

\section{DEVELOPMENT OF NOVEL TOOTHBRUSH TO PREVENT A PENETRATING INJURY OF CHILDREN}

1,2Yoshifumi Nishida, 1,2Koji Kitamura, 1,2Mikiko Oono, 'Tachio Takano, 1,2,3Tatsuhiro Yamanaka. 'National Institute of Advanced Industrial Science and Technology, Japan; ${ }^{2}$ Safe Kids Japan, Japan; ${ }^{3}$ Ryokuen Children's Clinic, Japan

\subsection{6/injuryprev-2016-042156.813}

Background Brushing teeth is an important hygiene practice in our lives. However, this practice sometimes causes a serious injury for children. According to a report from Tokyo Fire Department, Japan, 45 children under 5 on average admitted an emergency room by ambulance annually because of a penetrating injury by a toothbrush. A half of the cases occurred in 1 year old, and $75 \%$ of all cases occurred either in 1 or 2 years old. It is necessary to design a new innovative product which promotes children's self-reliance and prevent injury. The purpose of this study was to measure a force inside a mouth when a child brushes his or her teeth and fell down and to design a new product which can prevent a serious oral injury caused by fall.

Methods We developed a device to measure the force when a child falls while brushing teeth. A $2.65 \mathrm{~kg}$ weight which was the average weight of a child head was attached to a tip of toothbrush and let it fall from a height of $50 \mathrm{~cm}$. We put a piece of chicken meat under the toothbrush and then observed what happened to the meat. We used the chicken meat assuming inside of a mouth.

Results When the toothbrush with $2.65 \mathrm{~kg}$ weight was dropped, the maximum pressure in the toothbrush was about $15.6 \mathrm{MPa}$. Previous research clarified that the breaking stress of human skin is 3 to $15 \mathrm{MPa}$, and so this pressure is large enough to penetrate human skin.

Conclusions Based on our previous study, the time to fall is in only 0.5 second. A serious injury occurred in such short period of time. We collaborated with a corporate company dedicated to a safe toothbrush production and designed a "bendable" toothbrush. This toothbrush can bend when the pressure of $1.3[\mathrm{MPa}]$ at a maximum is applied to the brush while maintaining the capability of brushing. The pressure is smaller than the breaking stress of human skin. The new toothbrush allows us to prevent serious injury. This flexible toothbrush is commercialised in Japan since May, 2015.

\section{INJURY SEVERITY IN DIFFERENT TYPES OF PRODUCT INVOLVEMENT BASED ON INJURY SURVEILLANCE DATA ANALYSIS}

${ }^{1,2}$ Jesani Catchpoole, ${ }^{1}$ Kirsten Vallmuur, 'Sue Walker. 'Queensland University of Technology; ${ }^{2}$ Queensland Injury Surveillance Unit

10.1136/injuryprev-2016-042156.814

Background Severity of injury, as a measure of hazardous product consequences, is an essential aspect in the product safety risk assessment process. Moreover, the extent of product involvement in an injury event is also fundamental in order to determine the causality and preventability of the injury. While injury severity can be examined using coded injury data, product involvement is often omitted as coded data are limited to inform the level of product involvement in an injury event. However, text narratives data collected in emergency departments can potentially provide relevant product information. The study aimed to examine the severity of injuries and extent of product involvement in paediatric injuries in emergency department (ED) based injury surveillance data.

Methods A total of 7,743 paediatric injury cases were randomly selected from the Queensland Injury Surveillance Unit database and were manually reviewed and categorised according to the level of product involvement using the Product Involvement Factor classification system. Injury severity in these categories was then examined based on triage category and admission rate.

Results Overall, 44\% of all reviewed cases were associated with at least one type of consumer product. Based on the triage scoring, product-related injuries had a lower proportion of high severity injuries compared to non-product injuries. Within the product-related groups, injuries associated with high intrinsic risk products had the highest proportion of high severity injuries based on triage scoring (8\%) and injuries associated with maladapted or misused products had the highest admission rate after the emergency treatment (20\%).

Conclusions The urgency of injuries and the need for further treatment as severity measures vary depending on the level of product involvement. This highlights the need to account for product involvement and injury severity in order to inform a better understanding of product-related injuries in product safety prioritizations. Hence, emergency department data should be utilised to support product safety initiatives.

\section{INJURIES RELATED TO PRODUCT MISIDENTIFICATION ERROR: A SECONDARY ANALYSIS OF QUEENSLAND INJURY SURVEILLANCE DATA}

1,2Jesani Catchpoole, ' ${ }^{1}$ Ruth Barker. ' Queensland Injury Surveillance Unit; '2Queensland University of Technology, Centre for Accident Research and Road Safety - Queensland

\subsection{6/injuryprev-2016-042156.815}

Background There are growing safety concerns around consumer product misidentification errors. As incidents are thought to be under-reported to the product safety authority, it is difficult to quantify the extent of the issue. Injury surveillance data can be utilised to identify such injuries, using a combination of narrative text and coded data analysis. This study aimed to identify product misidentification incidents that resulted in injuries and to retrieve any details relating to the injury circumstances using the text narrative.

Methods A secondary data analysis was conducted using Queensland Injury Surveillance data collected over 15 year period (1999-2013). Product misidentification injuries were identified through text search using relevant keywords. The text narrative of all cases identified were then manually reviewed to validate and categorise the product misidentification error by the type of product, whether or not the product had been decanted, and whether it was a dosing error.

Results Overall, 158 cases were validated as relating to product misidentification. Around $61 \%$ of these cases were related to primary misidentification due to resemblance between two different 
products and around $16 \%$ were related to secondary product misidentification, where the exposure product had been decanted from the original packaging. Although product misidentification injuries were identified in all age groups, almost half of the cases were amongst children under the age of 10 years old, with the unintended product being administered by an adult in $68 \%$ of these cases. The most common type of misidentification error identified in the data was cleaning products mistaken for consumable products $(10 \%)$ and essential oils mistaken for paediatric syrup medications (12\%).

Conclusion While injury surveillance data are unlikely to capture the full extent of this issue, the details extracted from text narrative data on trend and pattern of injuries related to product misidentification can potentially inform product safety regulators.

\section{HEALTH SUPPLEMENT USE AND RELATED ADVERSE HEALTH EVENTS IN DUBAI: A POPULATION-BASED CROSS-SECTIONAL STUDY}

${ }^{1,2}$ Abdulla Naseem, ${ }^{1}$ Iain Blair, ${ }^{1}$ Adam Balazs. 'Institute of Public Health, College of Medicine and Health Sciences, United Arab Emirates University, United Arab Emirates; ${ }^{2}$ Consumer Products Safety SectionHead, Dubai Municipality, United Arab Emirates

\subsection{6/injuryprev-2016-042156.816}

Background Health supplement products (HS) that are on-sale in the Emirate of Dubai (United Arab Emirates) may contain ingredients and chemicals that may affect human health. This research aims to conduct a population based survey to identify the prevalence of HS consumption in the population of Dubai and the adverse health events related to their consumption.

Methods A population-based cross sectional household survey will assess the prevalence of HS product consumption and related adverse health effects. The survey will include both nationals and non-nationals aged 16 and above who live in Dubai and will be conducted in collaboration with Dubai Statistic Centre. Households will be randomly sampled from the sampling frame to give a sample of 600 nationals and 600 non-nationals which will ensure the desired precision. The survey will start in Feburary 2016, data will be colleceted from participants through a telephone interview and the survey is expected to be completed in two months.

Results The expected results of this study will provide important descriptive epidemiology on the prevalence of HS use and associated adverse health effects in Dubai. Study data is currently being collected and will be presented at the conference.

Conclusions With the increase in the use of HS products globally, the safety and efficacy of HS products have become a public health concern in Dubai. The strategic location of Dubai, an open market and the opportunities and conditions in the UAE promote the availability of such products in large amounts and the lack of data on exposure indicates the importance of this research.

\section{Drowning and Water Safety}

Post Tue 2.23

\section{EFFECTIVENESS OF VOLUNTEER BASED FIRST RESPONDER PROGRAM FOR PREVENTING DROWNING IN RURAL BANGLADESH}

${ }^{1}$ Mohammad Jahangir Hossain, ${ }^{1}$ Tom Mecrow, ${ }^{1}$ Fazlur Rahman, ${ }^{2}$ Imtiaz Ahamed, ${ }^{1}$ Kamran UI Baset, 'Animesh Biswas, 'Aminur Rahman. ${ }^{1}$ International Drowning Research Centre Bangladesh (IDRC-B); ${ }^{2}$ UNICEF Bangladesh

\subsection{6/injuryprev-2016-042156.817}

Background Health care facilities in rural areas are challenging in most developing countries. Bangladeshi people exposes to water for their daily life as a result child mortality \& morbidity due to drowning is higher than any other causes. In this paper trained community volunteers provided First responder services in managing drowning causalities were described.

Objective Assessment of the First Aid services provided by community volunteers in managing of drowning causalities in rural Bangladesh.

Methodology To deliver first aid services under SwimSafe program 1644 adolescent (male-741, female-903) were trained in different districts of Bangladesh. All volunteers received 2 days training using manual adopted from IDRC-B. All trainees had access of manikins to practice CPR. All volunteers were also trained on record keeping about the first aid services they provide. Trainings were conducted in between May to September and at the end of the year data was collected from the volunteers.

Results reports were collected from 844 instructors and services were provided among 4,648 causalities, of them 79 were due to drowning. Among the drowning causalities 70 were children. CPR was given to manage 23 causalities, among them 21 were children and 2 were adults. Of all 21 children $76 \%(\mathrm{n}=16)$ survived and 24\% $(\mathrm{n}=5)$ died. All the children were within 10 years of age. Volunteers treated 56 drowning casualties with keeping recovery position, of them 30 were boys \& 26 were girls. Among the 56 causalities $80 \%(n=49)$ were children. Of all drowning causalities 48 were referred for further treatment. Conclusion Bangladesh is a disaster prone area and the access of health care providers is very difficult in rural areas of Bangladesh so by developing adolescent based first responder it is possible to reduce drowning related mortality, morbidity disability.

Acknowledgement Contribution of UNICEF is acknowledged

\section{EFFECTIVENESS OF SEASAFE LIFEGUARD SERVICES IN COX'S BAZAR BEACH BANGLADESH}

'1 Jahangir Hossain, ${ }^{2}$ Tom Mecrow, ${ }^{2}$ Steve Wills, ${ }^{2}$ Darren Willims, ${ }^{1}$ Aminur Rahman, ${ }^{1}$ Fazlur Rahman. ${ }^{1}$ International Drowning Research Centre Bangladesh (IDRC-B); ${ }^{2}$ Royal National Lifeboat Institution (RNLI)

10.1136/injuryprev-2016-042156.818 